\title{
A Novel Machine Learning Strategy Based on Two-Dimensional Numerical Models in Financial Engineering
}

\author{
Qingzhen Xu \\ School of Computer Science, South China Normal University, Guangzhou 510631, China \\ Correspondence should be addressed to Qingzhen Xu; xqz1997@126.com
}

Received 23 October 2013; Revised 27 November 2013; Accepted 4 December 2013

Academic Editor: Gelan Yang

Copyright ( 2013 Qingzhen Xu. This is an open access article distributed under the Creative Commons Attribution License, which permits unrestricted use, distribution, and reproduction in any medium, provided the original work is properly cited.

\begin{abstract}
Machine learning is the most commonly used technique to address larger and more complex tasks by analyzing the most relevant information already present in databases. In order to better predict the future trend of the index, this paper proposes a twodimensional numerical model for machine learning to simulate major U.S. stock market index and uses a nonlinear implicit finitedifference method to find numerical solutions of the two-dimensional simulation model. The proposed machine learning method uses partial differential equations to predict the stock market and can be extensively used to accelerate large-scale data processing on the history database. The experimental results show that the proposed algorithm reduces the prediction error and improves forecasting precision.
\end{abstract}

\section{Introduction}

The operation of securities markets is changing at any time. More and more researchers on the stock market did a lot of research, which hopes to find the run law of the stock market [1]. Machine learning is programming computers to optimize a performance criterion using example data or past experience. However, the operation of the securities market is a very complex system; if you want to find out the operation of the internal laws of the stock market it is very difficult. It is widely acknowledged in machine learning that the performance of a learning algorithm is dependent on both its parameters and the training data.

Machine learning belongs to the field of artificial intelligence. The field's main objects of study are computer algorithms that improve their performance through experience. Machine learning focuses on prediction, based on known properties learned from the training data. In recent years, many scholars at home and abroad have made great contributions to the stock market forecasting in both empirical and theoretical work, which are necessary and sufficient for solving the financial engineering problem. For example, Chang et al. thought that using time series models to forecast stock index movements and make reasonably accurate predictions has two major drawbacks [1]. They forecasted the Taiwan stock exchange capitalization weighted stock index (TAIEX) by proposing a hybrid adaptive network based fuzzy inference system (ANFIS) model. Chu et al. proposed a dual-factor modified fuzzy time series model, which took stock index and traded volume as forecasting factors to predict stock index [2]. Xu presented a continuous time M/G/1 queue with multiple vacations and server close-down time [3]. Xu and Ma presented a discrete time Geo/G/1 queue with Bernoulli gated service simulation system [4]. Xu et al. proposed a theoretical model, but there was no practical application [5]. He et al. used established theoretical models to calculate cash flow in stock market research in 2011 [6]. However, He et al. can only calculate cash flow of the stock or the stock market but cannot solve the problem of forecasting the stock market [6]. Xu and Liu gave a strategy for forecasting average price and index of stocks using the algorithm of genetics, which applied the knowledge of statistics to choosing item by probability according to stock market, and they forecasted the volatility of Dow Jones Indexes and Standard \& Poor's 500 Indexes [7, 8]. However, there was some failure prediction from July 2011 to September 2011 in the decline phase. 
However the above research is not accurate in practice stock market. In order to better improve the forecasting accuracy, this paper focuses on improving the theoretical model.

Machine learning algorithms can be organized into a taxonomy based on the desired outcome of the algorithm or the type of input available during training the machine. Our goal of this paper is to use partial differential equations to predict the stock market. In order to study a practical simulation system to guide the investors to invest, this paper proposes a two-dimensional numerical model for machine learning to simulate major US stock market index and uses a heuristic two-dimensional mathematical simulation model with partial differential equations to simulate stock market index. The new machine learning method can be extensively used to accelerate large-scale data processing on the history database. The experimental results show that the proposed algorithm reduces the prediction error and improves forecasting precision.

The rest of this paper is organized as follows. Section 2 presents the model description. Section 3 presents the method of solution. Section 4 presents the simulation results of major U.S. stock market index and finally some conclusions are pointed out and future works are offered in Section 5.

\section{Two-Dimensional Numerical Models}

In this section, the proposed dimensional numerical models will be discussed. In general, dimensional numerical models in financial engineering can be described as follows.

Definition 1. Assume that $x$ represents the volume, $y$ represents the main index or stock's close price, $C_{c}$ represents the market activity, $\tau_{b}$ represents the rate of low price to close price, $\tau_{s}$ represents the rate of high price to close price, $\varepsilon_{b}$ represents the low price, $\varepsilon_{s}$ represents the high price, $\varepsilon_{c}$ represents the Tradable Market Capitalization rate, $\zeta_{1}$ represents the impact factor of low price, and $\zeta_{2}$ represents the impact factor of high price. The new dimensional numerical models can be formulated as

$$
\begin{gathered}
\frac{\partial U_{b}}{\partial t}=\frac{1}{\tau_{b}} \nabla \cdot\left(D_{b} \nabla U_{b}\right)-\xi_{1} \varepsilon_{b} \Gamma_{c}, \\
\frac{\partial U_{s}}{\partial t}=\frac{1}{\tau_{s}} \nabla \cdot\left(D_{s} \nabla U_{s}\right)-\xi_{2} \varepsilon_{s} \Gamma_{c}, \\
C_{c} \frac{\partial T}{\partial t}=\nabla \cdot\left(K_{\text {mix }} \nabla T\right)+\varepsilon_{c} \Gamma_{c}\left(\xi_{1} \lambda_{c}+\xi_{2} \lambda_{s}\right),
\end{gathered}
$$

in which $t$ represents the time $(t>0), \Gamma_{c}$ represents the day turnover rate, $\lambda_{c}$ represents the volume of business of high price, and $\lambda_{s}$ represents the low price individually, respectively. $\zeta_{1}=\varepsilon_{b} / \varepsilon_{s}, \zeta_{2}=\varepsilon_{c} / \varepsilon_{s}, \varepsilon_{b}=\sqrt{\varepsilon_{b x}^{2}+\varepsilon_{b y}^{2}}, \varepsilon_{s}=$ $\sqrt{\varepsilon_{s x}^{2}+\varepsilon_{s y}^{2}}, \varepsilon_{b}+\varepsilon_{s}+\varepsilon_{c}=1, \tau_{b}, \tau_{s} \in(0,1)$.

Definition 2. Assume that $U_{b}$ represents the Dow Jones Indexes, $U_{s}$ represents the Standard \& Poor's 500 Index, $T$ represents the NASDAQ Composite Index, $D_{b x}$ represents efficient change rate of the low price to volume, $D_{b y}$ represents efficient change rate of the low price to close price, $D_{s x}$ represents efficient change rate of the high price to volume, $D_{s y}$ represents efficient change rate of the high price to close price, $K_{x}$ represents the impact factor of open price, and $K_{y}$ represents the impact factor of close price. The related numerical model can be formulated as

$$
\begin{aligned}
\frac{\partial\left(C_{b} \varepsilon_{b}\right)}{\partial t}=\frac{1}{\tau_{b}}[ & \frac{\partial}{\partial x}\left(D_{b x} \frac{\partial\left(C_{b} \varepsilon_{b x}\right)}{\partial x}\right) \\
& \left.+\frac{\partial}{\partial y}\left(D_{b y} \frac{\partial\left(C_{b} \varepsilon_{b y}\right)}{\partial y}\right)\right]-\varepsilon_{b} \zeta_{1} \Gamma_{c}, \\
\frac{\partial\left(C_{s} \varepsilon_{s}\right)}{\partial t}=\frac{1}{\tau_{s}}\left[\frac{\partial}{\partial x}\left(D_{s x} \frac{\partial\left(C_{s} \varepsilon_{s x}\right)}{\partial x}\right)\right. & \left.+\frac{\partial}{\partial y}\left(D_{s y} \frac{\partial\left(C_{s} \varepsilon_{s y}\right)}{\partial y}\right)\right]-\varepsilon_{s} \zeta_{2} \Gamma_{c} \\
C_{c} \frac{\partial T}{\partial t}= & \frac{\partial}{\partial x}\left(K_{x} \frac{\partial T}{\partial x}\right)+\frac{\partial}{\partial y}\left(K_{y} \frac{\partial T}{\partial y}\right) \\
& +\varepsilon_{c} \Gamma_{c}\left(\zeta_{1} \lambda_{c}+\zeta_{2} \lambda_{s}\right),
\end{aligned}
$$

in which $\varepsilon_{b x}$ represents the rate of low price's volume to day volume, $\varepsilon_{b y}$ represents the rate of low price's volume to close price's volume, $\varepsilon_{s x}$ represents the rate of high price's volume to day volume, and $\varepsilon_{s y}$ represents the rate of high price's volume to close price's volume. $U_{s}=C_{s}(x, y, t) \varepsilon_{s}$, $U_{b}(x, y, t)=C_{b}(x, y, t) \varepsilon_{a}$.

\section{Description of the Proposed Algorithm}

The solution domain is $[x, y], x$ is the forecast time horizon, and $y$ is the price index range. The solution domain is divided into intervals $h_{1}, h_{2}$ in the direction of the forecast time horizon $x$, the price index range $y$. So $x_{i}=i h_{1}\left(I_{1}=1\right)$. $y_{j}=j h_{2}\left(J h_{2}=1\right), \operatorname{vol}_{i j}$ is the $i \times j$ th unit volume. $\left(U_{b}\right)_{i j}\left(x_{i}, y_{j}\right)$ is denoted by $\left(U_{b}\right)_{i j}$ and $\left(U_{s}\right)_{i j}\left(x_{i}, y_{j}\right)$ is denoted by $\left(U_{s}\right)_{i j}$. Considering a uniform grid, the spatial discretization of the solution domain in finite volume $i j$ is then

$$
\begin{aligned}
\int_{\mathrm{vol}_{i j}} \nabla \cdot\left(D_{b} \nabla U_{b}\right) d \mathrm{vol}_{i j} \\
=\int_{\mathrm{vol}_{i j}} \frac{\partial}{\partial x}\left(D_{b} \frac{\partial U_{b}}{\partial x}\right) d \operatorname{vol}_{i j}+\int_{\mathrm{vol}_{i j}} \frac{\partial}{\partial y}\left(D_{b} \frac{\partial U_{b}}{\partial y}\right) d \operatorname{vol}_{i j} \\
=\left(\left(D_{b}\right)_{(i+(1 / 2)) j k}\left(\left(U_{b}\right)_{(i+1) j k}-\left(U_{b}\right)_{i j k}\right)\right. \\
\left.\quad-\left(D_{b}\right)_{(i-(1 / 2)) j k}\left(\left(U_{b}\right)_{i j k}-\left(U_{b}\right)_{(i-1) j k}\right)\right) \times\left(h_{1}\right)^{-1} \\
\quad+\left(\left(D_{b}\right)_{i(j+(1 / 2)) k}\left(\left(U_{b}\right)_{i(j+1) k}-\left(U_{b}\right)_{i j k}\right)\right. \\
\left.\quad-\left(D_{b}\right)_{i(j-(1 / 2)) k}\left(\left(U_{b}\right)_{i j k}-\left(U_{b}\right)_{i(j-1) k}\right)\right) \times\left(h_{2}\right)^{-1}
\end{aligned}
$$




$$
\begin{aligned}
\int_{\mathrm{vol}_{i j}} \nabla \cdot\left(D_{s} \nabla U_{s}\right) d \mathrm{vol}_{i j} \\
=\int_{\mathrm{vol}_{i j}} \frac{\partial}{\partial x}\left(D_{s} \frac{\partial U_{s}}{\partial x}\right) d \mathrm{vol}_{i j}+\int_{\mathrm{vol}_{i j}} \frac{\partial}{\partial y}\left(D_{s} \frac{\partial U_{s}}{\partial y}\right) d \mathrm{vol}_{i j} \\
=\left(\left(D_{s}\right)_{(i+(1 / 2)) j k}\left(\left(U_{s}\right)_{(i+1) j k}-\left(U_{s}\right)_{i j k}\right)\right. \\
\left.\quad-\left(D_{s}\right)_{(i-(1 / 2)) j k}\left(\left(U_{s}\right)_{i j k}-\left(U_{s}\right)_{(i-1) j k}\right)\right) \times\left(h_{1}\right)^{-1} \\
+\left(\left(D_{s}\right)_{i(j+(1 / 2)) k}\left(\left(U_{s}\right)_{i(j+1) k}-\left(U_{s}\right)_{i j k}\right)\right. \\
\left.\quad-\left(D_{s}\right)_{i(j-(1 / 2)) k}\left(\left(U_{s}\right)_{i j k}-\left(U_{s}\right)_{i(j-1) k}\right)\right) \times\left(h_{2}\right)^{-1} \\
\int_{\mathrm{vo}_{i j}}^{\nabla} \cdot\left(K_{\text {mix }} \nabla T\right) d \mathrm{vol}_{i j} \\
=\int_{\mathrm{vo}_{i j}} \frac{\partial}{\partial x}\left(K_{\text {mix }} \frac{\partial T}{\partial x}\right) d \mathrm{vol}_{i j}+\int_{\mathrm{vol}_{i j}} \frac{\partial}{\partial y}\left(K_{\text {mix }} \frac{\partial T}{\partial y}\right) d \mathrm{vol}_{i j} \\
=\left(\left(K_{\text {mix }}\right)_{(i+(1 / 2)) j k}\left((T)_{(i+1) j k}-(T)_{i j k}\right)\right. \\
\left.\quad-\left(K_{\text {mix }}\right)_{(i-(1 / 2)) j k}\left((T)_{i j k}-(T)_{(i-1) j k}\right)\right) \times\left(h_{1}\right)^{-1} \\
+\left(\left(K_{\text {mix }}\right)_{i(j+(1 / 2)) k}\left((T)_{i(j+1) k}-(T)_{i j k}\right)\right. \\
\left.\quad-\left(K_{\text {mix }}\right)_{i(j-(1 / 2)) k}\left((T)_{i j k}-(T)_{i(j-1) k}\right)\right) \times\left(h_{2}\right)^{-1} .
\end{aligned}
$$

These results are from the cell volume, $\operatorname{vol}_{i j}$ being equal to $h_{1} h_{2}$. The limited efficient change rates are considered. The method is implemented as

$$
\begin{gathered}
\left(D_{b}\right)_{(i+(1 / 2)) j k}=\varepsilon_{b}\left(D_{b}\right)_{(i-(1 / 2)) j k}+\left(1-\varepsilon_{b}\right)\left(D_{c}\right)_{(i-1 / 2)) j k}, \\
\left(D_{b}\right)_{i(j+(1 / 2)) k}=\varepsilon_{b}\left(D_{b}\right)_{i(j-(1 / 2)) k}+\left(1-\varepsilon_{b}\right)\left(D_{c}\right)_{i(j-(1 / 2)) k} \\
\left(D_{s}\right)_{(i+(1 / 2)) j k}=\frac{\gamma \cos \theta \sin ^{2} \alpha d_{c}\left(\varepsilon_{s}\right)_{(i-(1 / 2)) j k}^{1 / 3}}{20 \eta\left(\varepsilon_{s}\right)_{(i-(1 / 2)) j k}^{1 / 3}}, \\
\left(D_{s}\right)_{i(j+(1 / 2)) k}=\frac{\gamma \cos \theta \sin ^{2} \alpha d_{c}\left(\varepsilon_{s}\right)_{i(j-(1 / 2)) k}^{1 / 3}}{20 \eta\left(\varepsilon_{s}\right)_{i(j-(1 / 2)) k}^{1 / 3}} .
\end{gathered}
$$

The fully implicit Newton-Krylov (NK) method is based on a first-order forward Euler time integration. In the method we converge the nonlinearities within a time step thus we need a time step index $k$ and a nonlinear iteration index $n$. The first-order accurate time integration method is

$$
\begin{gathered}
\frac{\left(U_{b}\right)_{i j(k+1)}^{n}-\left(U_{b}\right)_{i j k}}{\delta}-\left(\frac{\partial}{\partial x}\left(\left(D_{b}\right)_{i j(k+1)}^{n} \frac{\partial\left(U_{b}\right)_{i j(k+1)}^{n}}{\partial x}\right)\right. \\
\left.+\frac{\partial}{\partial y}\left(\left(D_{b}\right)_{i j(k+1)}^{n} \frac{\partial\left(U_{b}\right)_{i j(k+1)}^{n}}{\partial y}\right)\right) \\
=-\left(\xi_{1}\right)_{i j(k+1)}^{n}\left(\varepsilon_{c}\right)_{i j(k+1)}^{n}\left(\Gamma_{c}\right)_{i j(k+1)}^{n},
\end{gathered}
$$

$$
\begin{gathered}
\frac{\left(U_{s}\right)_{i j(k+1)}^{n}-\left(U_{s}\right)_{i j k}}{\delta}-\left(\frac{\partial}{\partial x}\left(\left(D_{s}\right)_{i j(k+1)}^{n} \frac{\partial\left(U_{s}\right)_{i j(k+1)}^{n}}{\partial x}\right)\right. \\
\left.+\frac{\partial}{\partial y}\left(\left(D_{s}\right)_{i j(k+1)}^{n} \frac{\partial\left(U_{s}\right)_{i j(k+1)}^{n}}{\partial y}\right)\right) \\
=-\left(\xi_{2}\right)_{i j(k+1)}^{n}\left(\varepsilon_{c}\right)_{i j(k+1)}^{n}\left(\Gamma_{c}\right)_{i j(k+1)}^{n}, \\
\frac{(T)_{i j(k+1)}^{n}-(T)_{i j k}}{\delta}-\left(\frac{\partial}{\partial x}\left(\left(K_{\text {mix }}\right)_{i j(k+1)}^{n} \frac{\partial(T)_{i j(k+1)}^{n}}{\partial x}\right)\right. \\
\left.+\frac{\partial}{\partial y}\left(\left(K_{\text {mix }}\right)_{i j(k+1)}^{n} \frac{\partial(T)_{i j(k+1)}^{n}}{\partial y}\right)\right) \\
=\left(\varepsilon_{c}\right)_{i j(k+1)}^{n}\left(\Gamma_{c}\right)_{i j(k+1)}^{n}\left(\left(\xi_{1}\right)_{i j(k+1)}^{n}\left(\lambda_{c}\right)_{i j(k+1)}^{n}\right. \\
\left.+\left(\xi_{2}\right)_{i j(k+1)}^{n}\left(\lambda_{s}\right)_{i j(k+1)}^{n}\right) .
\end{gathered}
$$

Concentrating on the solution of the two-dimensional simulation model of major U.S. stock market index, we find that the nonlinear function plays an important role in describing the algorithm and monitor convergence. The nonlinear iteration is implemented with an inexact, matrixfree Newton-Krylov method $[9,10]$. By defining the nonlinear functions to differentiate them, we get the discredited equations at each grid cell.

We use $F_{i j}^{A}$ function to compute Dow Jones Industrial Average $\left(U_{b}\right)$ at segmentation cell $i, j, F_{i j}^{L}$ function to compute S \& P $500\left(U_{s}\right)$ at segmentation cell $i, j$, and $F_{i j}^{T}$ function to simulate the NASDAQ Composite Index $(T)$ at segmentation cell $i, j$, which are described as follows:

$$
\begin{aligned}
& F_{i j}^{A}=\int_{\mathrm{vol}_{i j}}\left[\frac{\left(U_{b}\right)_{i j(k+1)}^{n}-\left(U_{b}\right)_{i j k}}{\delta}\right. \\
& -\left(\frac{\partial}{\partial x}\left(\left(D_{b}\right)_{i j(k+1)}^{n} \frac{\partial\left(U_{b}\right)_{i j(k+1)}^{n}}{\partial x}\right)\right. \\
& \left.+\frac{\partial}{\partial y}\left(\left(D_{b}\right)_{i j(k+1)}^{n} \frac{\partial\left(U_{b}\right)_{i j(k+1)}^{n}}{\partial y}\right)\right) \\
& \left.+\left(\xi_{1}\right)_{i j(k+1)}^{n}\left(\varepsilon_{c}\right)_{i j(k+1)}^{n}\left(\Gamma_{c}\right)_{i j(k+1)}^{n}\right] d \operatorname{vol}_{i j}, \\
& F_{i j}^{L}=\int_{\mathrm{vol}_{i j}}\left[\frac{\left(U_{s}\right)_{i j(k+1)}^{n}-\left(U_{s}\right)_{i j k}}{\delta}\right. \\
& -\left(\frac{\partial}{\partial x}\left(\left(D_{s}\right)_{i j(k+1)}^{n} \frac{\partial\left(U_{s}\right)_{i j(k+1)}^{n}}{\partial x}\right)\right. \\
& \left.+\frac{\partial}{\partial y}\left(\left(D_{s}\right)_{i j(k+1)}^{n} \frac{\partial\left(U_{s}\right)_{i j(k+1)}^{n}}{\partial y}\right)\right) \\
& \left.+\left(\xi_{2}\right)_{i j(k+1)}^{n}\left(\varepsilon_{c}\right)_{i j(k+1)}^{n}\left(\Gamma_{c}\right)_{i j(k+1)}^{n}\right] d \operatorname{vol}_{i j} \text {, }
\end{aligned}
$$




$$
\begin{aligned}
F_{i j}^{T}=\int_{\mathrm{vol}_{i j}} & \frac{(T)_{i j(k+1)}^{n}-(T)_{i j k}}{\delta} \\
& -\left(\frac{\partial}{\partial x}\left(\left(K_{\text {mix }}\right)_{i j(k+1)}^{n} \frac{\partial(T)_{i j(k+1)}^{n}}{\partial x}\right)\right. \\
& \left.+\frac{\partial}{\partial y}\left(\left(K_{\text {mix }}\right)_{i j(k+1)}^{n} \frac{\partial(T)_{i j(k+1)}^{n}}{\partial y}\right)\right) \\
- & \left(\varepsilon_{c}\right)_{i j(k+1)}^{n}\left(\Gamma_{c}\right)_{i j(k+1)}^{n} \\
& \times\left(\left(\xi_{1}\right)_{i j(k+1)}^{n}\left(\lambda_{c}\right)_{i j(k+1)}^{n}\right. \\
& \left.\left.+\left(\xi_{2}\right)_{i j(k+1)}^{n}\left(\lambda_{s}\right)_{i j(k+1)}^{n}\right)\right] d \operatorname{vol}_{i j} .
\end{aligned}
$$

\section{Machine Learning and Data Mining of Major U.S. Stock Market Index}

In this section, we simulate the U.S. stock market. All data are from the United States public securities market information. We apply the above mathematical model to get the future of the U.S. stock market index chart.

4.1. U.S. Stock Market Trend Forecast in One Year. From Figure 1, we know that Dow Jones Index fell all the way down from early September 2011 to November 20, 2011 or so. The Dow Jones index would arrive at the bottom end in November 20,2011 , and be about to usher in a wave of a strong rebound. The rebound starting from November 20, 2011 will continue to April 20, 2012. Dow Jones Index will reach the bottom of 9500 and will rise 30 percent. At April 20, 2012, DJI will arrive at 12269. In 2012 from April 20 to July 20 only, Dow Jones Index will enter a phase of slow decline. The Dow Jones Index would have reached 10830 in July 20. The Dow Jones Index would rise to start a new round just from July 20. This wave of the market rally will continue until December 20. The Dow Jones Index would reach 13000 in December 20. The second rally is twenty percent of the rate of increase. However, it is not very good in the second phase of rising, and especially there would be a small drop from August 20 to October 20.

From Figure 2, we can see that Standard \& Poor's 500 index fell all the way down from early September 2011 to November 23, 2011 or so. Standard \& Poor's 500 Index would arrive at the bottom end in November 23, 2011, and be about to usher in a wave of a strong rebound. The rebound starting from November 23, 2011 will continue to April 12, 2012. Standard \& Poor's 500 will reach the bottom of 1017 in November 23, 2011 around and will rise 30 percent in the next 4 months. At April 12, 2012, Standard \& Poor's 500 will arrive at 1325 . Standard \& Poor's 500 will enter a phase of slow decline from April 12 to July 18 in 2012. Standard \& Poor's 500 would reach 1190 in July 18 . Standard \& Poor's 500 would rise to start a new round just from July 18. This wave of the market rally will continue until December 12 . Standard \& Poor's 500 would reach 1429 in December 12. The second rally is twenty percent of the rate of increase. However, it is not very good

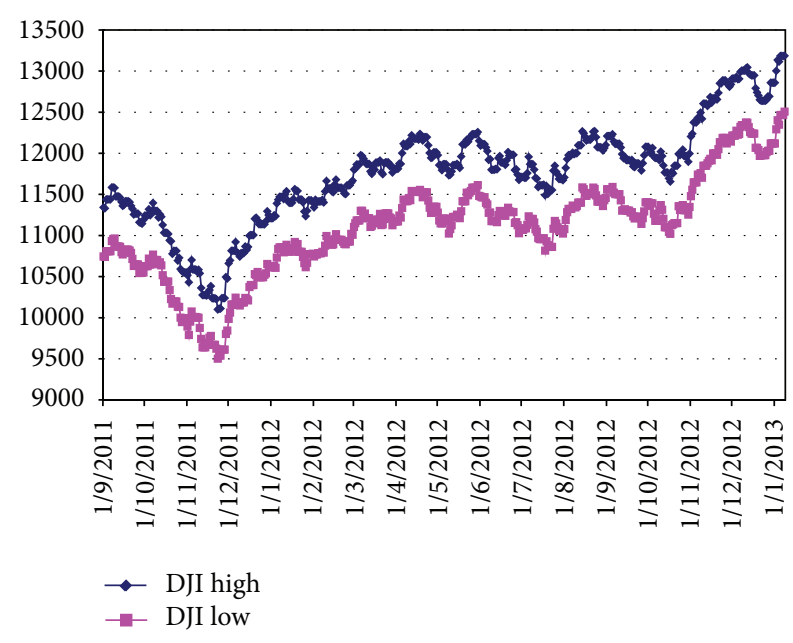

Figure 1: Dow Jones Indexes daily forecast chart for one year.

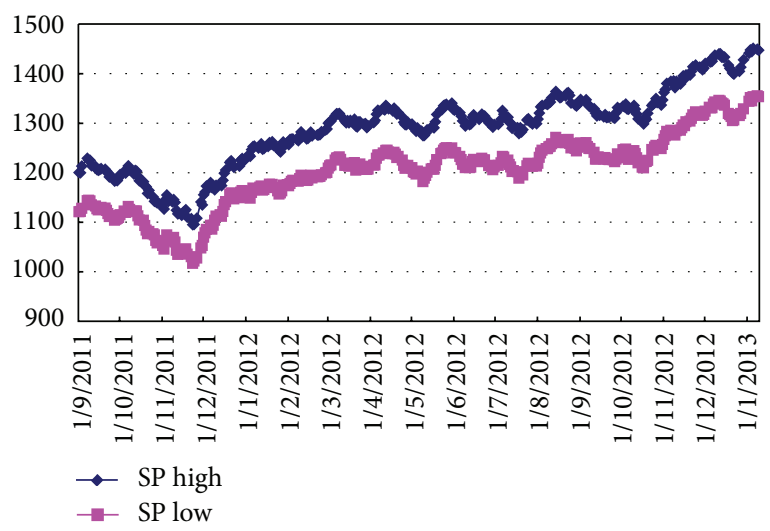

FIgure 2: Standard \& Poor's 500 Index daily forecast chart for one year.

in the second phase of rising, and especially there would be a small drop from August 15 to October 15.

From Figure 3, we find that the NASDAQ index would be sideways trend shocks between 2400 and 2700 from early September 2011 to December 1, 2011 or so. The NASDAQ index would usher in a wave of mad cow market rally from December 1, 2011 to February 13, 2012. The market would rise 29 percent. The NASDAQ index would reach a high of 3145 in mid-February 2012. From mid-February 2012, the NASDAQ index would enter the downward trend. It will reach the bottom of 2574 in June 30, 2012. The NASDAQ index would enter the sideways trend shock from July 1 to October 5 in 2012. During this period, the NASDAQ index would swing between 2600 and 2900. The NASDAQ index would begin a bull market from 2600 as a starting point. The NASDAQ index would reach the high point of 3295 in the end of 2012. There would be 27 percent increase.

4.2. U.S. Stock Market Trend Forecast in Four Years. From Figure 4, we can see that Dow Jones Indexes would arrive at the bottom in the end of November 2011. From the end 


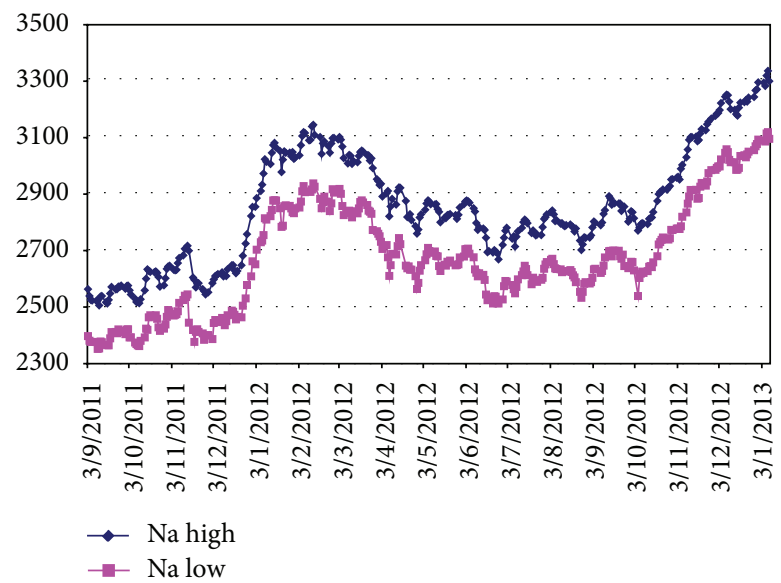

FIGURE 3: NASDAQ Index daily forecast chart for one year.

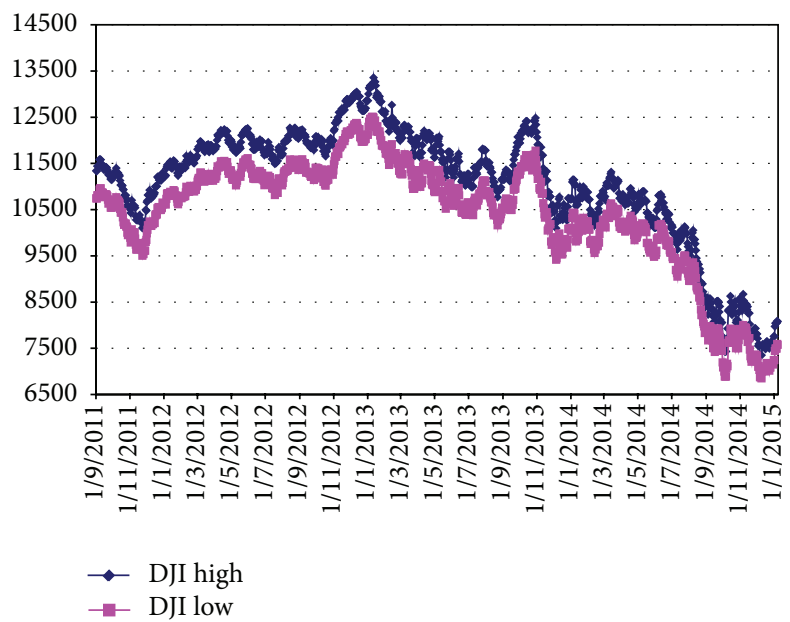

FIgURE 4: Dow Jones Indexes daily forecast chart in four years.

of November 2011 to early January 2013, Dow Jones Indexes would be a bull market. There would be a forty percent increase during the rising trend. From early January 2013 to early December 2014, Dow Jones Indexes would be a long stock market crash. The decline of the stock market crash would reach fifty percent. It is very terrible, and the stock market crash would be similar with the 2008 financial crisis.

From Figure 5, we know that Standard \& Poor's 500 Index would arrive at the bottom in the end of November 2011. From the end of November 2011 to mid-December 2012, Standard \& Poor's 500 Index would be a bull market. There would be about forty percent increase during the rising trend. From early January 2013 to the end of October 2014, Standard \& Poor's 500 Indexes would be a long stock market crash. The decline of the stock market crash would reach forty-seven percent. The stock market crash would be similar with the 2008 financial crisis. It would be below 700 .

From Figure 6, we know that the NASDAQ Index would be a sideways process from early September to December 1 in 2011. The NASDAQ Index would be a bull market rally from December 1, 2011 to February 13, 2012. From February

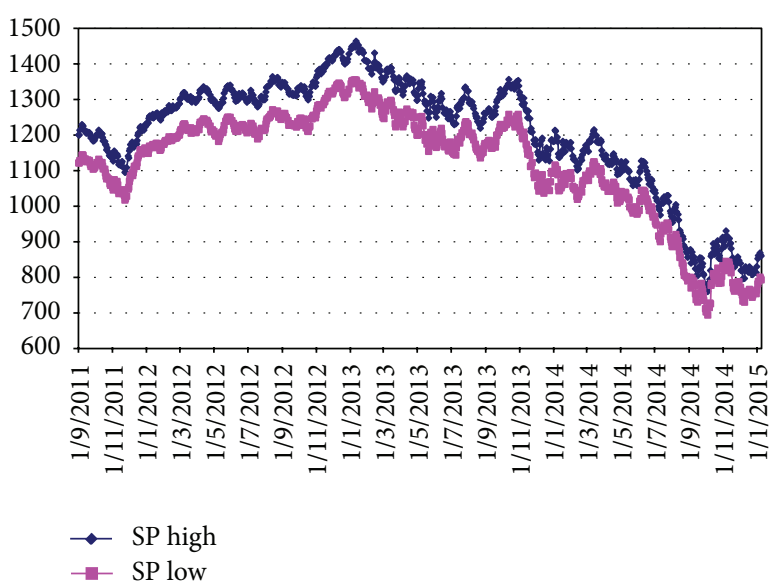

FIgURE 5: Standard \& Poor's 500 Index daily forecast chart in four years.

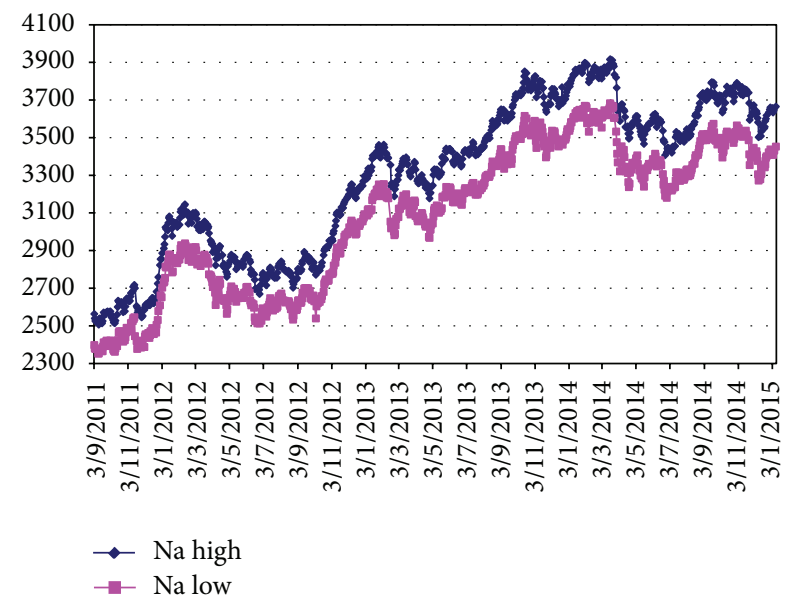

FIGURE 6: NASDAQ Index daily forecast chart in four years.

13, 2012 to April 28, 2012, the NASDAQ Index would be a bear market decline. The NASDAQ Index would be a bottoming process from May 1, 2012 to October 5, 2012. It would be up to 5 months during the bottoming period. The NASDAQ Index would experience a rising market from early October 2012 to the end of January 2013. From early February 2013 to late April 2013, The NASDAQ Index would experience a down market. The NASDAQ Index would experience a longer period of rising prices from early May 2013 to the end of January 2014. From early February 2014 to the end of June 2014, the NASDAQ Index would experience a down market. Then the NASDAQ Index would enter the market downturn. All in all, it would be a rising trend from the end of 2012 to early 2014 .

4.3. Summary of Future Market Trends. From Figures 1-6, we found that DJI and S\&P 500 are highly correlated. The NASDAQ Index would take the independent market. We can conclude the future trend as Table 1 .

From Table 1, we can see that NASDAQ trend is different with DJI and S\&P 500. We conducted in-depth analysis. When the bear market is coming, the first small-cap stocks 
TABLE 1: Different periods with different trends in U.S. stock market index.

\begin{tabular}{lcccc}
\hline Period & DJI & S\&P 500 & NASDAQ & Conclusion \\
\hline 2011.9.1 2011.11.30 & Down & Down & Sideways & NASDAQ are better than DJI and S\&P 500 \\
2011.11.30 2013.2.1 & Up & Up & First up, second down, again up & NASDAQ would have a complex trend \\
2011.11.30 2012.2.13 & Up & Up & UP & All up \\
2013.2 2014.12 & Stock crash & Stock crash & Sideways & Active in the Nasdaq Capital Market \\
\hline
\end{tabular}

would go into the bear market faster than large-cap stocks. On the contrary, when the bull market is coming, the first smallcap stocks would go into the bull market faster than large-cap stocks. In the U.S. stock market, the Dow Jones Index comes to the bull market and reaches the top peak, and NASDAQ will enter bear market or that bull market faster than DJI. While most people know that the bull market arrived, smallcap stocks have little chance. Then large-cap stocks rise up and small-cap stocks come to fall. Dow Jones Index is on behalf of big business and NASDAQ Index is on behalf of small business. We can understand the reason of different trends between NASDAQ and DJI.

\section{Conclusions}

The computational analysis of machine learning algorithms and their performance is a branch of theoretical computer science known as computational learning theory. This paper proposes a two dimensional numerical model for machine learning to simulate major U.S. stock market index and uses a nonlinear implicit finite-difference method to find numerical solutions of the two-dimensional simulation model. The new machine learning method can be extensively used to accelerate large-scale data processing on the history database. We substantially increase the investment rate of return in the securities market investment practice based on the above machine learning result. In the future, we will investigate European stock markets and Asian stock markets. In addition, the proposed machine learning algorithm and two dimensional numerical models will be applied to the more financial fields.

\section{Acknowledgment}

The authors gratefully acknowledge the helpful comments and suggestions of the reviewers, which have improved the presentation.

\section{References}

[1] J.-R. Chang, L.-Y. Wei, and C.-H. Cheng, "A hybrid ANFIS model based on AR and volatility for TAIEX forecasting," Applied Soft Computing Journal, vol. 11, no. 1, pp. 1388-1395, 2011.

[2] H.-H. Chu, T.-L. Chen, C.-H. Cheng, and C.-C. Huang, "Fuzzy dual-factor time-series for stock index forecasting," Expert Systems with Applications, vol. 36, no. 1, pp. 165-171, 2009.

[3] Q. Xu, "Continuous time M/G/1 queue with multiple vacations and server close-down time," Journal of Computational Information Systems, vol. 3, no. 2, pp. 753-757, 2007.
[4] Q. Xu and Z. Ma, "Discrete time Geo/G/1 queue with Bernoulli gated service simulation system," Applied Mathematics and Computation, vol. 204, no. 1, pp. 37-44, 2008.

[5] Q. Xu, S. Bao, Z. Ma, and N. Tian, " $M^{x} / G / 1$ queue with multiple vacations," Stochastic Analysis and Applications, vol. 25, no. 1, pp. 127-140, 2007.

[6] C. He, Y. Liu, and Q. Xu, "Research on Chinese stock market's money flow by two-stage model," Management World, vol. 2, no. 3, pp. 16-26, 2011.

[7] Q. Xu, "A new algorithm to forecast Shanghai composite index," Journal of Information and Computational Science, vol. 7, no. 12, pp. 2463-2467, 2010.

[8] Q. Xu and Y. Liu, "A genetic algorithms to forecast American shares price index," Journal of Information and Computational Science, vol. 8, no. 8, pp. 1245-1250, 2011.

[9] P. N. Brown and Y. Saad, "Hybrid Krylov methods for nonlinear systems of equations," SIAM Journal on Scientific and Statistical Computing, vol. 11, no. 3, pp. 450-481, 1990.

[10] D. A. Knoll, W. J. Rider, and G. L. Olson, "An efficient nonlinear solution method for non-equilibrium radiation diffusion," Journal of Quantitative Spectroscopy \& Radiative Transfer, vol. 63, no. 1, pp. 15-29, 1999. 


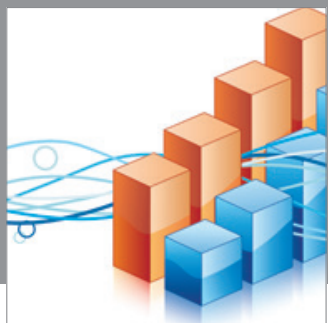

Advances in

Operations Research

mansans

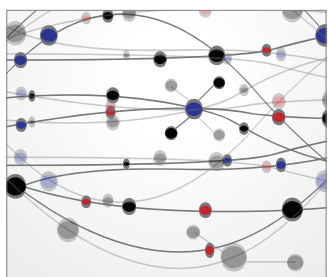

The Scientific World Journal
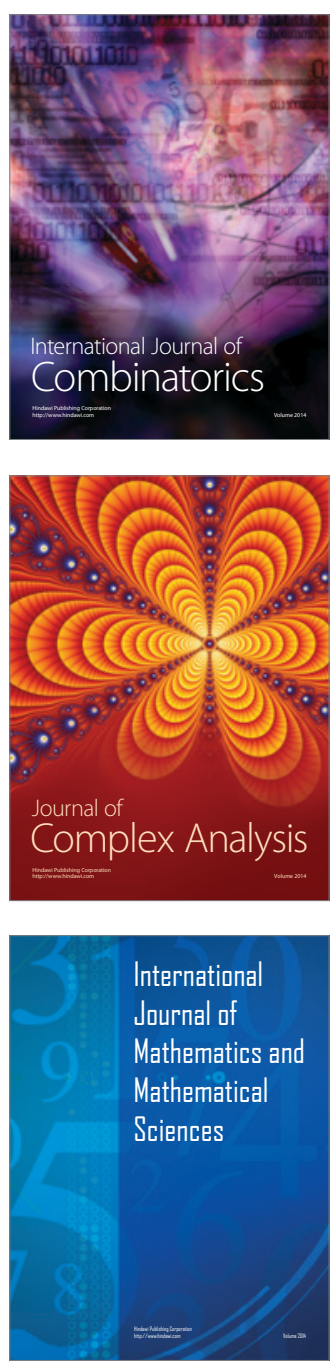
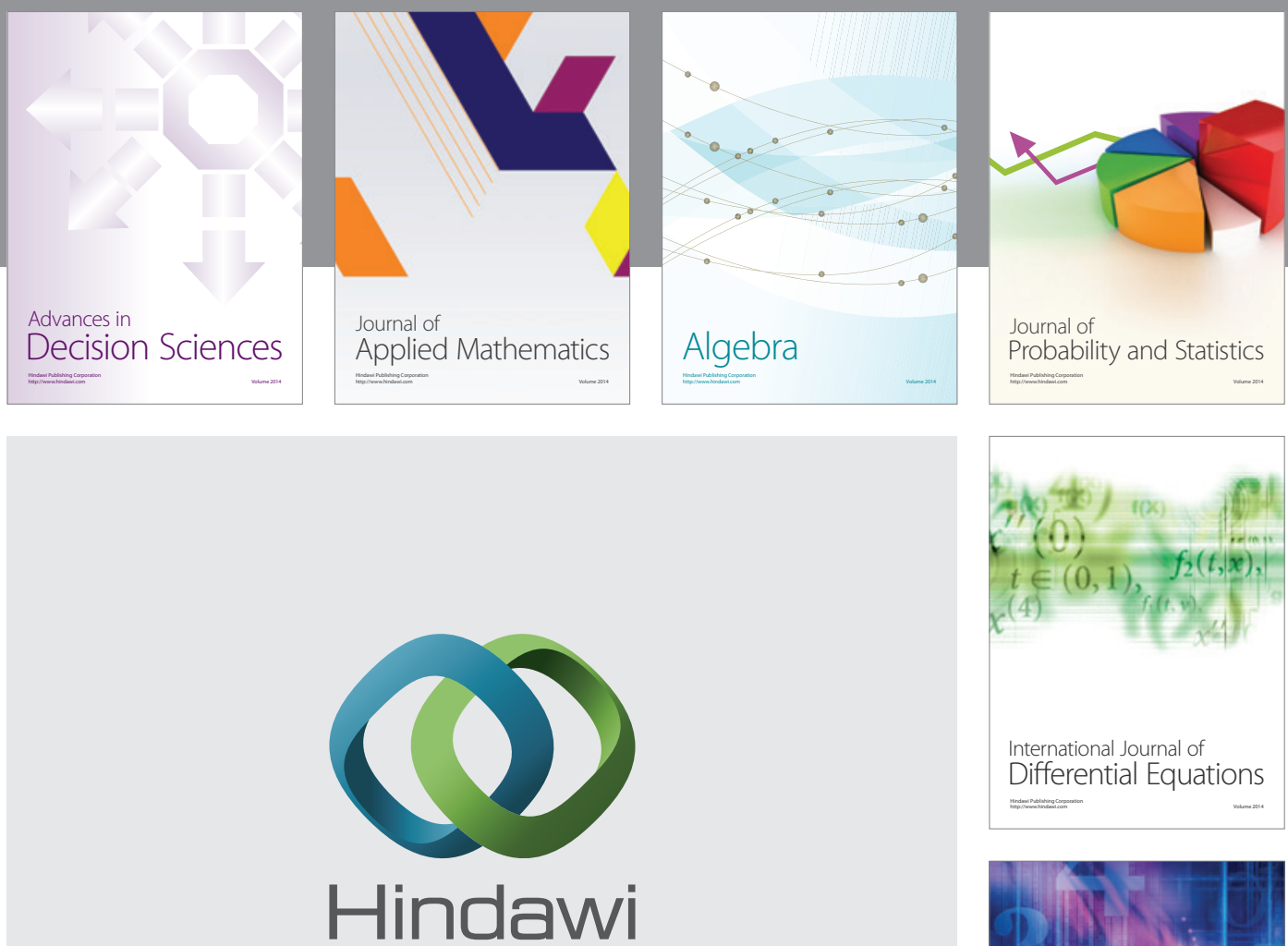

Submit your manuscripts at http://www.hindawi.com
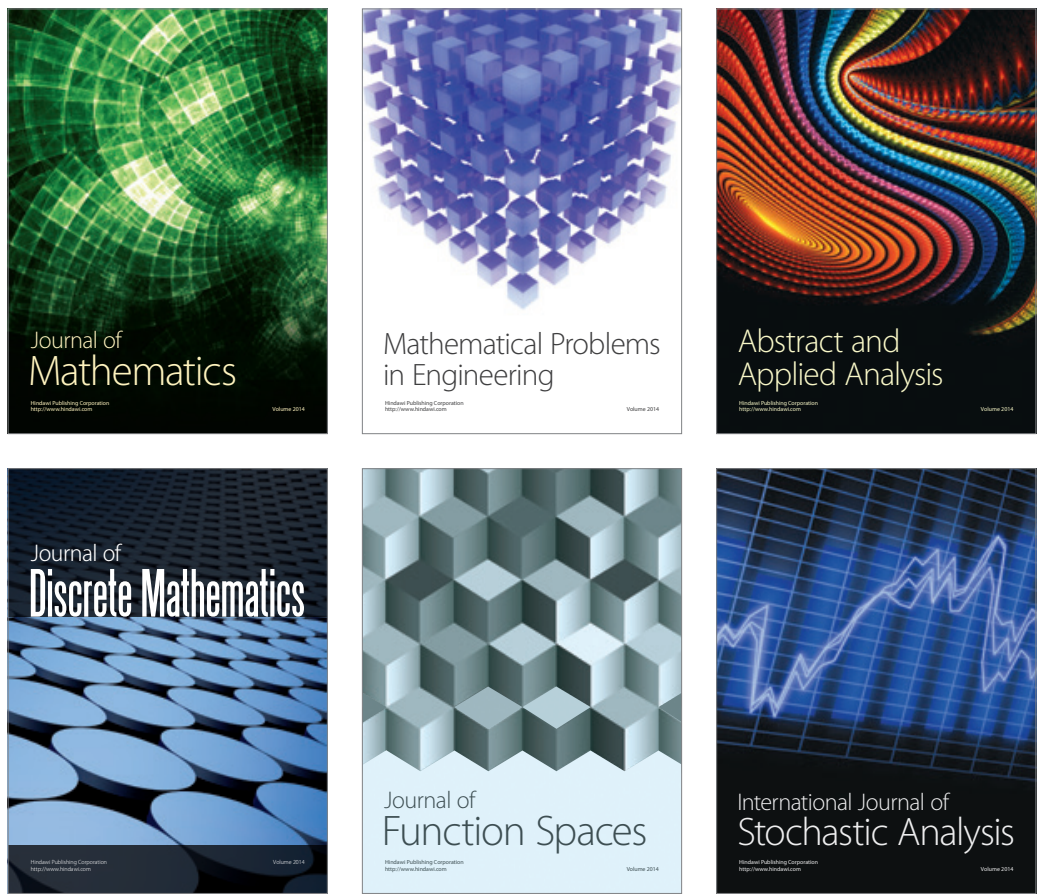

Journal of

Function Spaces

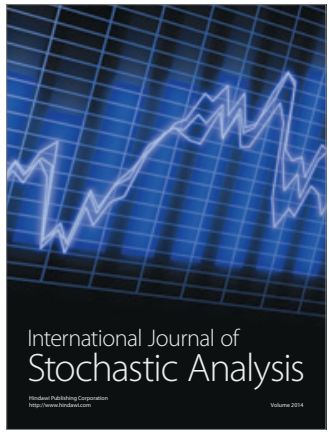

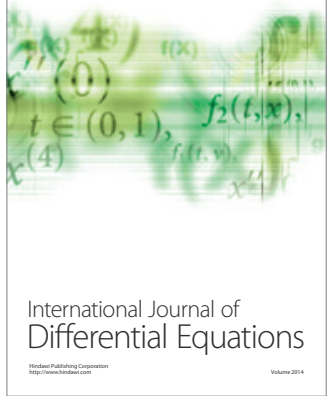
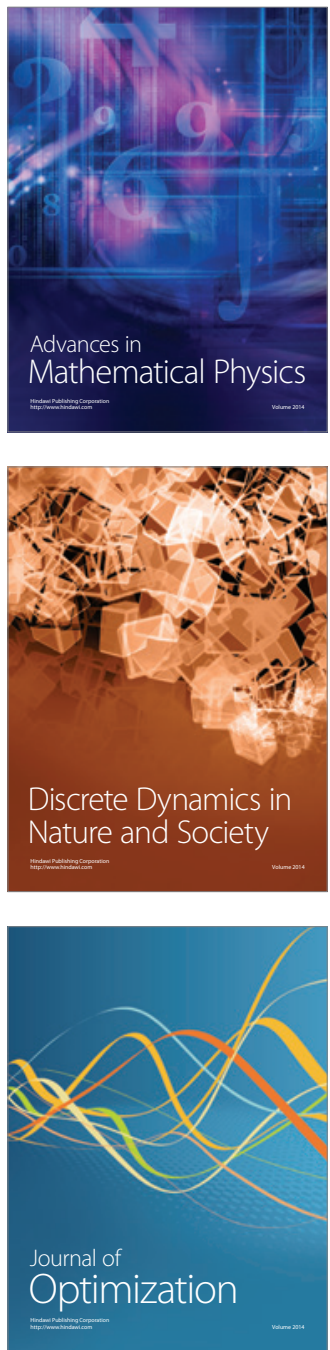